\title{
INTERPROFESSIONAL EDUCATION (IPE) DALAM KURIKULUM PENDIDIKAN KESEHATAN SEBAGAI STRATEGI PENINGKATAN KUALITAS PELAYANAN MATERNITAS
}

\author{
INTERPROFESSIONAL EDUCATION (IPE) IN HEALTH EDUCATION \\ CURRICULUM AS A STRATEGY TO IMPROVE THE QUALITY OF \\ MATERNITY CARE
}

\author{
Endah Sulistyowati \\ Program Studi Kebidanan, Universitas Muhammadiyah Semarang \\ Email : endah@unimus.ac.id
}

\begin{abstract}
ABSTRAK
Interprofessional education (IPE) telah dimulai di beberapa negara maju seperti Kanada, Inggris, Amerika, dan Australia sejak 53 tahun yang lalu. Penerapan IPE dalam kurikulum pendidikan kesehatan telah terbukti memberikan dampak positif terhadap peningkatan keterampilan komunikasi dan teamwork dari tenaga kesehatan. Penelitian ini merupakan Literature review yang bertujuan untuk mengeksplorasi dampak dari penerapan pendidikan interprofesi di kurikulum pendidikan kesehatan dalam peningkatan kualitas pelayanan maternitas. Artikel yang direview didapatkan melalui pencarian di data base elektronik seperti MEDLINE (OVID) 1996, CINAHL, and ERIC (EBSCO) menggunakan kata kunci seperti interprofessional education, curriculum, midwifery, dan maternity care. Selain itu, pencarian secara manual di Journal of Interprofessional care juga dilakukan. Penelusuran artikel dibatasi hanya terbitan tahun 2009-2018. Dari penelusuran tersebut, didapatkan bahwa penerapan pendidikan interprofesi dalam kurikulum Pendidikan kesehatan dapat meningkatkan keterampilan komunikasi dan bekerja sama dalam tim yang merupakan kompetensi utama dalam praktik kolaborasi antar profesi kesehatan. Keterampilan ini sangat mendukung peningkatan pelayanan maternitas. Ego profesi, perbedaan budaya profesi, penjadwalan, sumberdaya pengajar, dan persepsi tentang IPE ditemukan sebagai hambatan dalam penerapan IPE. Dukungan dari institusi, kepemimpinan, dan lingkungan Pendidikan yang kondusif merupakan faktor pendukung terlaksananya IPE di institusi Pendidikan. Metode pembelajaran IPE yang dapat diterapkan dalam kurikulum kebidanan diantaranya: OSCE, diskusi studi kasus, praktik komunitas dan kegiatan ekstrakurikuler.
\end{abstract}

Kata Kunci: Interprofessional education, kurikulum kebidanan, pelayanan kebidanan

\section{ABSTRACT}

Interprofessional education has been inisiated by some developed countries such as Canada, United Kingdom, USA, and Australia since 53 years ago. The implementation of IPE in healthcare education curriculum has been proven giving positive impact to the improvement of the health care practitioners' communication and teamwork skills. This study is a literature review which is aimed to eksplore the impact of IPE implementation in health education curriculum in the improvement of the quality of maternity care. The reviewed articles are found from electronic databases searching such as MEDLINE (OVID) 1996, CINAHL, and ERIC (EBSCO) using some key words: interprofessional education, curriculum, midwifery, dan maternity care. Manual searching was also done through Journal of Interprofessional care. Articles were limited by the publishing year of 2009-2018. From the review found that the implementation of IPE in healthcare education curriculum improved the communication and teamwork skills which are the core competences of collaborative practice among heath practitioners. Those skills are supporting the 
improvement of maternity care. Profession ego, differential of professional cultures, scheduling, teaching resources, and the perception of IPE are found to be the challenges in implementing IPE. Institutional support, Leadership, and the condusive education environment are the supporting factors of the implementation of IPE. IPE teaching methods can be used in midwifery curriculum such as OSCE, case study, community practice, and extracurricular activities.

Keywords: interprofessional education, midwifery curriculum, midwifery care

\section{PENDAHULUAN}

Tenaga kesehatan adalah profesional dengan berbagai keterampilan dalam memberikan pelayanan kesehatan yang berkualitas dan berfokus pada kesehatan pasien (Frenk et al., 2010). Di era globalisasi ini, tenaga kesehatan dituntut untuk menyediakan layanan kesehatan yang prima dan berkualitas (Kenda, C.et al., 2011). Sistem kesehatan di seluruh dunia saat ini sedang mengalami kondisi krisis (Frenk et al., 2010). Distribusi tenaga kesehatan yang tidak merata berdampak terhadap layanan kesehatan yang terfragmentasi (IOM, 2011). Kondisi ini menyebabkan tidak terpenuhinya kebutuhan akan layanan kesehatan di daerahdaerah tertentu. Jika masalah ini tidak segera diatasi, akan menjadi penghalang utama untuk mencapai Tujuan Pembangunan Berkelanjutan (SDGs) (Noguchi, I., 2014). Pemerintah di seluruh dunia mencari solusi inovatif dan transformasi sistem yang akan memastikan pasokan, pemerataan, dan distribusi tenaga kerja kesehatan yang sesuai (IOM, 2011). Salah satu solusi yang menjanjikan adalah penerapan kolaborasi interprofesi (Reeves et al., 2007).

Menurut Canadian Interprofessional Health Collaborative (CIHC) (2010) kolaborasi interprofesi terjadi ketika profesional kesehatan bekerja sama dengan rekan kerja, profesi lain, pasien dan dengan keluarga mereka.

Setelah hampir 50 tahun penelitian, didapatkan banyak penelitian yang membuktikan bahwa praktik kolaborasi yang efektif antar profesi kesehatan dapat mengoptimalkan layanan kesehatan, memperkuat sistem kesehatan dan meningkatkan outcomes kesehatan (IOM, 2015). Praktik kolaborasi juga dapat mengurangi jumlah komplikasi, lama rawat inap, konflik antara tim kesehatan, dan angka kematian (Frenk et al., 2010). Tidak adanya kolaborasi yang baik di antara petugas kesehatan akan memiliki dampak negatif pada pasien, pemborosan sumber daya dan penurunan kepuasan kerja (Freeth, 2001).

Keterampilan komunikasi sebagai bagian dari praktik kolaborasi juga memainkan peran penting untuk menghasilkan pelayanan berkualitas (Barr, H,et al., 2015). Salah satu masalah komunikasi yang dapat ditemukan dalam praktek klinis adalah pekerjaan yang tumpang tindih dalam tim interprofessional yang disebabkan oleh komunikasi yang tidak efektif di antara anggota tim yang kemudian mempengaruhi outcome pasien (Frenk et al., 2010). Komisi gabungan (JCAHO) melaporkan bahwa dua pertiga dari insiden kesalahan medis disebabkan oleh komunikasi yang buruk antara tenaga kesehatan (D'amour dan Oandasan, 2005). Temuan ini menunjukkan betapa pentingnya implementasi kolaborasi di antara petugas kesehatan untuk meningkatkan kualitas layanan kesehatan. Namun, praktik kolaborasi dengan mudah terjadi. Diperlukan proses untuk membuat petugas kesehatan mampu bekerja dalam tim dan berkomunikasi secara efektif (Barr, H,et al., 2015). 
Untuk menghadapi tantangan yang semakin kompleks dari kebutuhan dan masalah kesehatan, konferensi Institute of Medicine (IOM) yang pertama merekomendasikan agar semua penyedia pendidikan kesehatan diwajibkan untuk mendorong kerjasama antar profesi kesehatan dalam tim pelayanan kesehatan (Antonakis, J, 2012). Pendidikan adalah kunci untuk mengembangkan dan mengubah metode dan kualitas layanan kesehatan (Causack, T and O'Donoghue., 2012). Namun pada kenyataannya, pelatihan dan pendidikan untuk mempersiapkan praktisi kesehatan dalam menerapkan perawatan berbasis tim belum sepenuhnya dilaksanakan. Hal ini dinyatakan dalam laporan IOM, bahwa dalam praktik layanan kesehatan, pekerja kesehatan dituntut untuk bekerja dalam tim interdisiplin, tetapi mereka belum menerima pelatihan dan pendidikan yang sesuai (IOM, 2015).

Akademisi kesehatan memiliki peran dan tanggung jawab untuk memberikan pendidikan dan pelatihan bagi mahasiswa kesehatan dengan kompetensi layanan berbasis tim (Capella et al., 2010). Dalam proses ini, pemerintah, akademisi dan pembuat kebijakan harus menentukan visi yang jelas tentang pendidikan dan program kesehatan berkualitas yang memenuhi standarstandar ini (Benner et al., 2010). Untuk menciptakan praktik kolaboratif dan meningkatkan outcomes kesehatan, satu atau lebih profesional yang berbeda harus memahami peran dan fungsi profesinya serta memahami peran profesi kesehatan lain (Causack, T and O'Donoghue., 2012). Pendidikan interprofesi adalah cara yang efektif untuk mengembangkan keterampilan kolaborasi antara tenaga kesehatan yang nantinya siap bekerja sama untuk memberikan perawatan komprehensif dalam berbagai pelayanan kesehatan (Hall dan Zierler, 2015).

\section{METODE PENELITIAN}

Penelitian ini merupakan Literature review yang bertujuan untuk mengeksplorasi dampak dari penerapan IPE di kurikulum pendidikan kebidanan dalam peningkatan kualitas pelayanan kebidanan.

Proses review dimulai dengan mengidentifikasi jurnal artikel yang relevan dengan topik penelitian. Artikel yang akan direview didapatkan melalui pencarian di data base elektronik seperti MEDLINE (OVID) 1996, CINAHL, and ERIC (EBSCO).

Artikel yang akan direview dalam penelitian ini mencakup penelitian kualitatif maupun kuantitatif yang meneksplorasi pelaksanaan IPE dalam Pendidikan kebidanan dan dampaknya pada pelayanan kebidanan. Artikel memuat hasil penelitian dari negara-negara maju yang telah lama menerapkan IPE.

Pencarian artikel menggunakan kata kunci seperti interprofessional education, effectiveness of IPE, IPE impact, curriculum, midwifery, midwifery education, interprofessional collaboration, collaborative practice, midwifery care dan maternity care. Selain itu, pencarian secara manual di Journal of Interprofessional care juga dilakukan. Penelusuran artikel dibatasi hanya terbitan tahun 2009-2018 dan diterbitkan dalam bahasa Inggris.

\section{HASIL DAN PEMBAHASAN}

Pencarian literatur melalui data base elektronik menghasilkan 86 artikel yang berpotensi untuk direview. Setelah mengidentifikasi abstrak dari 86 artikel, terpilihlah 17 artikel. Identifikasi selanjutnya dilakukan dengan lebih detail untuk 
menentukan artikel yang relevan dan memenuhi kriteria inklusi dalam literature review ini. Dari identifikasi ini didapatkan 5 artikel yang akan direview dalam penelitian ini. Proses identifikasi artikel dapat dilihat pada diagram 1.

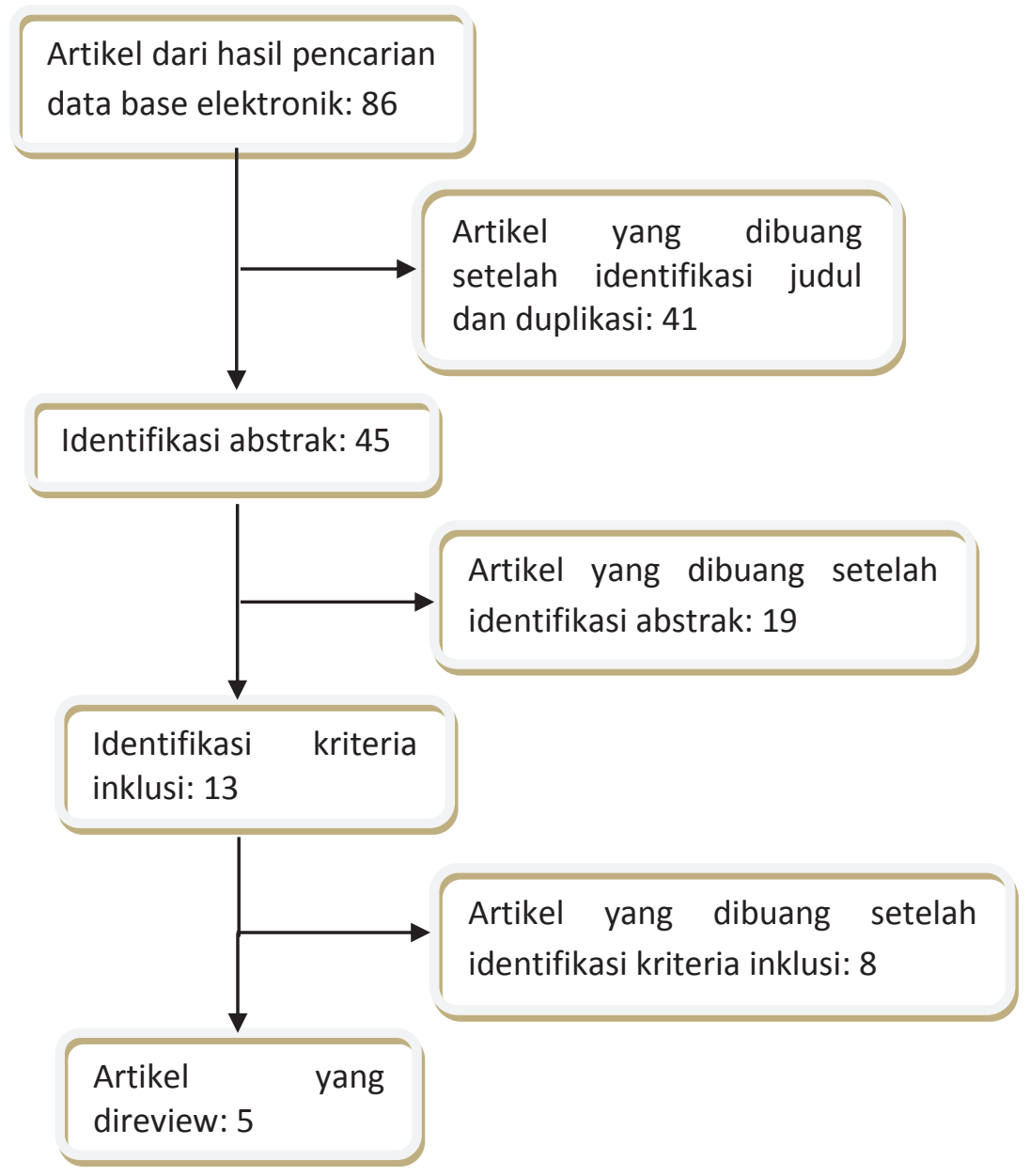

Diagram 1. Proses identifikasi artikel

Lima artikel yang terpilih untuk direview dalam penelitian ini merupakan hasil penelitian dari berbagai negara maju, yaitu Inggris (Billie Hunter, B and Segrott, J, 2014), California (Margaret, H et al 2011), Belanda (Romijn, A, et al 2017), Swiss (Shamian, J, 2014), dan Australia (Lapkin, S., et al, 2013). Artikel yang berasal dari Indonesia tidak ditemukan karena masih minimnya penerapan IPE dalam kurikulum Pendidikan kesehatan di Indonesia. Tiga dari lima artikel tersebut merupakan penelitian kualitatif dengan metode wawancara, focus group dan deskripsi, sedangkan dua artikel yang lain menggunakan metodologi penelitian kuantitatif secara cross sectional dan meta-analisis. Penerapan IPE dalam kurikulum Pendidikan Kesehatan dibahas dalam hasil penelitian dari Lapkin, S et al. (2013), sedangkan empat artikel lain menggambarkan dampak positif dari penerapan IPE di tahap akademik. Ringkasan dari artikel yang direview dalam penelitian ini dapat dilihat di Tabel 1 berikut: 
Table 1. Ringkasan Artikel yang direview

\begin{tabular}{|c|c|c|c|}
\hline Penulis & Negara & Judul Penelitian & Metode penelitian \\
\hline $\begin{array}{l}\text { Hunter, B } \\
\text { and } \\
\text { Segrott, J, } \\
2014\end{array}$ & Inggris & $\begin{array}{l}\text { Renegotiating inter- } \\
\text { professional boundaries } \\
\text { in maternity care: } \\
\text { implementing a clinical } \\
\text { pathway for normal } \\
\text { labour }\end{array}$ & $\begin{array}{l}\text { Kualitatif, etnografi } \\
\text { (wawancara, focus } \\
\text { groups) }\end{array}$ \\
\hline
\end{tabular}

$\begin{array}{ll}\text { Margaret, California } & \text { Great Minds Don't Kualitatif, Deskriptif } \\ \mathbf{H} \text { et al } & \text { Think Alike: } \\ \text { 2011 } & \text { Collaborative } \\ & \text { Maternity Care at San } \\ & \text { Francisco General } \\ & \text { Hospital } \\ & \text { communications }\end{array}$

\begin{tabular}{|c|c|c|}
\hline $\begin{array}{l}\text { Romijn, Belanda } \\
\text { A, et al } \\
\mathbf{2 0 1 7}\end{array}$ & $\begin{array}{l}\text { Interprofessional } \\
\text { collaboration among } \\
\text { care professionals in } \\
\text { obstetrical care: are } \\
\text { perceptions aligned? }\end{array}$ & $\begin{array}{l}\text { Kuantitatif, } \\
\text { sectional }\end{array}$ \\
\hline
\end{tabular}

Hasil mewakili karakteristik pekerjaan bidan sebagai pendukung persalinan normal dan meningkatkan kepercayaan diri dan visibilitas bidan dalam menjalankan

profesionalisme pekerjaan. Namun, hal ini juga menjadi pembatas antara bidan dan dokter obsgyn.

Kerjasama dan kolaborasi yang baik antara bidan dan dokter spesialis kandungan tercipta dengan mempertahankan nilainilai profesionalisme, kemandirian, dan saling ketergantungan.

Penelitian ini menemukan perbedaan yang relevan dalam proses kolaborasi antar profesi kesehatan dalam pelayanan obstetric di Belanda. Pelayanan kebidanan saaat ini sedang dirombak menjadi pelayanan yang terintegrasi sehingga membutuhkan kolaborasi yang efektif antar profesi kesehatan.

\begin{tabular}{|c|c|c|c|c|}
\hline $\begin{array}{l}\text { Shamian, } \\
\text { J, } 2014\end{array}$ & Swiss & $\begin{array}{l}\text { Interprofessional } \\
\text { collaboration, the only } \\
\text { way to Save Every } \\
\text { Woman and Every } \\
\text { Child }\end{array}$ & Kualitatif, Deskriptif & $\begin{array}{l}\text { Kolaborasi dan kerjasama } \\
\text { tim antar tenaga kesehatan } \\
\text { dalam pelayanan } \\
\text { maternitas sangat } \\
\text { dibutuhkan baik di tingkat } \\
\text { lokal, regional maupun } \\
\text { internasional. }\end{array}$ \\
\hline $\begin{array}{l}\text { Lapkin, } \\
\text { S., et al, } \\
2013\end{array}$ & Australia & $\begin{array}{l}\text { A Systematic review of } \\
\text { the effectiveness of } \\
\text { interprofessional } \\
\text { education in health } \\
\text { professional programs }\end{array}$ & $\begin{array}{l}\text { Kuantitatif, } \\
\text { analisis }\end{array}$ & $\begin{array}{lr}\text { Sikap dan } & \text { persepsi } \\
\text { mahasiswa } & \text { tentang } \\
\text { kolaborasi antarprofesi dan } \\
\text { pengambilan } & \text { keputusan } \\
\text { klinik dapat ditingkatkan } \\
\text { melalui IPE. }\end{array}$ \\
\hline
\end{tabular}

1. Penerapan IPE dalam kurikulum pendidikan kesehatan 
IPE yang juga dikenal dengan istilah interprofessional learning, merupakan suatu konsep Pendidikan yang direkomendasikan oleh World Health Organisation (WHO) sebagai Pendidikan terintegrasi untuk membangun kolaborasi antara tenaga kesehatan (WHO, 2010).

IPE terjadi ketika mahasiswa dari dua tau lebih profesi kesehatan belajar bersama, belajar dari profesi kesehatan lain, dan belajar tentang peran masing-masing profesi kesehatan untuk meningkatkan keterampilan kolaborasi dan kualitas pelayanan kesehatan (Parsell and Bligh, 2011). Menurut Speakman (2015), IPE bertujuan menghasilkan tenaga kesehatan yang memiliki pengetahuan, keterampilan, dan sikap yang mendukung praktik kolaborasi antarprofesi kesehatan.

Implementasi IPE dalam kurikulum Pendidikan kesehatan memiliki tiga fokus. Pertama, peningkatan pengetahuan, keterampilan, dan sikap mahasiswa dalam praktik kolaborasi antar profesi kesehatan. Kedua, berfokus pada pembelajaran tentang bagaimana menciptakan kolaborasi yang efektif dalam sebuah tim. Ketiga, menciptakan kerjasama yang efektif untuk meningkatkan kualitas pelayanan terhadap pasien (Lapkin, S, et al., 2013).

Berdasarkan penelitian Lapkin, et al. (2013), penerapan IPE harus dimulai pada tahap awal akademik mahasiswa, sebelum mereka menjadi seorang professional kesehatan. Hal ini diperkuat dengan hasil penelitian Thibault (2013), bahwa IPE harus dilaksanakan baik pada tahap akademik maupun praktik klinik dengan tujuan menghubungkan antara teori yang didapatkan mahasiswa selama pembelajaran di kampus dan praktik yang dijalani di lapangan, ini terbukti memberikan banyak manfaat bagi mahasiswa.

Pendekatan IPE memfasilitasi mahasiswa untuk belajar dari dan tentang disiplin kesehatan yang lain sehingga akan meningkatkan keterampilan mahasiswa dan menciptakan kerjasama yang lebih baik dalam sebuah lingkungan kerja yang terintegrasi (Lapkin, S, et al., 2013). Namun sangat disayangkan pelaksanaan IPE di institusi-institusi Pendidikan kesehatan sekarang masih belum konsisten. Untuk itu, penting kiranya membuat komitmen untuk menerapkan pembelajaran interprofesi di institusi Pendidikan kesehatan dan mengintegrasikan IPE ke dalam kurikulum Pendidikan kesehatan untuk memastikan keberlanjutan IPE.

2. Efektifitas IPE dalam peningkatan kualitas pelayanan maternitas.

Telah banyak hasil penelitian yang menunjukkan dampak positif pelaksanaan IPE dalam pendidikan kesehatan. Keuntungan yang didapat tidak hanya dari sisi pendidikan saja, tetapi juga dalam hal pelayanan kesehatan (Zwareinstein, 2009).

Dalam hal akademik, IPE membantu mahasiswa dalam peningkatan pengetahuan dan keterampilan yang spesifik, seperti pemecahan masalah dalam tim, konseling kesehatan, dan keterampilan klinik. Hal ini berpotensi untuk meningkatkan pemahaman, kepercayaan, dan saling menghargai antara profesi kesehatan, sehingga memungkinkan mahasiswa untuk mencapai kompetensi kolaboratif (Hall and Zierler, 2015).

Keuntungan penerapan IPE dalam pelayanan kesehatan didapat dari tercapainya kolaborasi yang lebih baik antara praktisi kesehatan (Margaret, H, 
et al., 2011). Pelayanan pasien harus dilihat sebagai suatu proses terintegrasi. IPE merupakan salah satu cara untuk mengintegrasikan keahlian tenaga kesehatan dari berbagai bidang dengan mendorong para professional kesehatan untuk berbagi pengetahuan dan bekerja dalam tim (Romijn, A, et al., 2017). Dengan adanya kolaborasi antar profesi kesehatan, dapat mengurangi overlapping pekerjaan, mempercepat pemberian layanan, dan menyediakan informasi yang lebih komprehensif bagi pasien (Shamian, J, 2014).

Bekerja secara kolektif dalam sebuah tim yang terdiri dari berbagai profesi kesehatan memungkinkan untuk berbagi beban kerja dan mengurangi pembatas antar profesi (Hunter, B and Segrott, J, 2014). Efek positif yang lain dari penerapan kolaborasi antarprofesi kesehatan yaitu memudahkan tenaga kesehatan untuk memiliki pengetahuan dan keterampilan yang lebih luas sehingga mereka dapat menyelesaikan berbagai macam tugas. Hal ini akan menciptakan suasana kerja yang lebih efektif dan mengoptimalkan sumber daya manusia yang ada (Romijn, A, et al., 2017).

Beberapa penelitian telah membuktikan dampak positif dari penerapan kolaborasi antar profesi kesehatan dalam pelayanan maternitas. Salah satunya, adalah penelitian yang dilakukan oleh Margaret, H, et al. (2011) mendeskripsikan keberhasilan rumah sakit di San Fransisco, California dalam memberikan pelayanan yang prima kepada ibu dan bayi yang dicapai dengan adanya kolaborasi yang baik antara dokter obgyn dan bidan selama lebih dari 30 tahun. Kolaborasi yang bertahan lama antara bidan dan dokter obsgyn ini ditopang dengan persamaan nilai, tujuan, dan komitmen untuk memberikan pelayanan yang unggul bagi pasien dan juga melakukan kaderisasi dengan melatih generasi bidan dan dokter selanjutnya dengan pola yang sama. Selain itu, keberhasilan juga dikaitkan dengan adanya rasa saling menghargai perbedaan antar profesi dan memanfaatkan keahlian masing-masing profesi secara maksimal.

\section{KESIMPULAN}

Efektivitas IPE dalam menciptakan tenaga kesehatan yang professional, mampu bekerjasama dan berkolaborasi dengan profesi kesehatan yang lain, menghargai dan memahami profesi kesehatan lain, telah dibuktikan dari banyaknya penelitian terkait. Dalam pelayanan maternitas, kemampuan kolaborasi dan bekerjasama antara bidan dan dokter spesialis kandungan sangat dibutuhkan untuk menghasilkan pelayanan yang berkualitas sehingga menghasilkan outcome yang bagus bagi ibu dan bayi. Untuk itu, penerapan IPE dalam pendidikan kesehatan di Indonesia sangat direkomendasikan dalam rangka mewujudkan palayanan kesehatan, termasuk pelayanan kesehatan maternitas yang lebih berkualitas. 


\section{DAFTAR PUSTAKA}

Antonakis, J. (2012). Transformational and transactional leadership. In D. Day and J. Antonakis (eds) The nature of Leadership ( $2^{\text {nd }}$ edn). Thousand Oaks, CA: Sage.

Barr H, Freeth D, Hammick M, Koppel I, Reeves S (2015) The evidence base and recommendations for interprofessional education in health and social care. J Interprof Care 20: 75-78.

Benner, P., Sutphen, M., Leonard, V., \& Day, L. (2010). Educating nurses: A call for radical transformation. San Francisco, CA: Jossey-Bass.

Canadian Interprofessional Health Collaborative (CIHC). (2010). A national interprofessional competency framework. Retrieved from http://www.cihc.ca (accessed 11 April 2017).

Capella, J., Smith, S., Philp A, Putnam, T., Gilbert, C., and Fry, W. (2010). Teamwork training improves the clinical care of trauma patients. Journal of Surgery Education, 67, 439-443. doi:10.1016/j.jsurg.2010.06.006.

Cusack, T and O'Donoghue, G. (2012). The introduction of an interprofessional education module: students' perceptions. Quality in Primary Care 2012;20:231-8.

D'amour, D., \& Oandasan, I. (2005). Interprofessionality as the field of interprofessional practice and interprofessional education: An emerging concept, Journal of Interprofessional Care, 19 (Suppl 1), 8-20.

Frenk, J., L. Chen, Z. A. Bhutta, J. Cohen, N. Crisp, T. Evans, H. (2010). Health professionals for a new century: Transforming education to strengthen health systems in an interdependent world. Lancet 376(9756):19231958.

Hall, L. W., \& Zierler, B. K. (2015). Interprofessional Education and Practice Guide No. 1; Developing faculty to effectively facilitate interprofessional education. Journal of Interprofessional Care, 29(1), 3-7. doi:10.3109/13561820.2014.937483.

Hunter, B and Segrott, J.(2014). Renegotiating inter-professional boundaries in maternity care: implementing a clinical pathway for normal labour. Sociology of Health \& Illness (36):5. pp. 719-737 doi: 10.1111/14679566.12096

Institute of Medicine. (2011). The future of nursing: Leading change, advancing health. Washington, DC: The National Academies Press.

Institute of Medicine, (2015). Measuring the impact of interprofessional education (IPE) on collaborative practice and patient outcomes. Washington DC: National Academies Press.

Kenda C, Jenny M and Katharine K. (2011). Innovations and action research to develop research skills for nursing and midwifery practice:the Innovations in Nursing and Midwifery Practice Project study. Journal of Clinical Nursing, 21, 1716-1725, doi: 10.1111/j.13652702.2011.03936.x 
Lapkin, S., et al, (2013). A Systematic review of the effectiveness of interprofessional education in health professional programs. Nurse Education Today: 33. p 90-102. doi:10.1016/j.nedt.2011.11.006

Margaret, H et al. (2011). Great Minds Don't Think Alike: Collaborative Maternity Care at San Francisco General Hospital communications. Obstetrics \& Gynecology:118(3).p 678-682 doi: 10.1097/AOG.0b013e3182297d2d

Noguchi, I. (2014). Miscommunication a major cause of medical error, study shows. State of Health. Retrieved from http://ww2.kqed.org/stateofhealth/2014/11/25/miscommunicationamajor-cause-of-medical-error-study-shows/.

Parsell G and Bligh J. (2011). The development of a questionnaire to assess the readiness of health care students for interprofessional learning (RIPLS). Med Educ 33(2):95-100.

Reeves, S., Goldman, J., \& Oandasan. (2007). Key factors in planning and implementing interprofessional education in health care settings. Journal of Allied Health, 36(4), 231-235.

Romijn, A, et al. (2017). Interprofessional collaboration among care professionals in obstetrical care: are perceptions aligned?. British Medical Journal Quality and Safety;0:1-8. doi:10.1136/bmjqs-2016006401

Shamian, J, (2014). Interprofessional collaboration, the only way to Save Every Woman and Every Child. www.thelancet.com.vol.284. Online/Series http://dx.doi.org/10.1016/ S0140-6736(14)60919-3 and http://dx.doi.org/10.1016/ S0140-6736(14)60930-2

Speakman, E., \& Sicks, S. (2015). Nursing in the 21st century: Find opportunities to practice in interprofessional healthcare teams. NSNA Imprint, 35-37.

Thibault, G. E. (2013). Reforming health professions education will require culture change and closer ties between classroom and practice. Health Affairs, 32(11), 1928-1932.

World Health Organization (WHO). (2010). Framework for action on interprofessional education \& collaborative practice. Geneva: World Health Organization.

Zwarenstein M, Goldman J, Reeves S. (2009). Interprofessional collaboration: effects of practice-based interventions on professional practice and healthcare outcomes: Systematic review. Cochrane Database of Systematic Reviews, Issue 3. Art. No.: CD000072. DOI: 10.1002/14651858.CD000072.pub2. 